\title{
Extraintestinal manifestations of Crohn's disease: prevalence and related factors
}

\author{
A. Repiso, M. Alcántara, C. Muñoz-Rosas, R. Rodríguez-Merlo'1, M. J. Pérez-Grueso, J. M. Carrobles and \\ J. L. Martínez-Potenciano
}

Departments of Gastroenterology and 'Anatomical Pathology. Hospital Virgen de la Salud. Toledo, Spain

\begin{abstract}
Background: patients with inflammatory bowel disease may suffer one or more extraintestinal manifestations during the course of their condition, these being more frequent in Crohn's disease. The aim of our study was to evaluate the prevalence of extraintestinal manifestations in patients with Crohn's disease in our healthcare area, and to assess the relationship between its presence and diverse clinical-evolutionary variables.

Material and methods: extraintestinal manifestations in 157 patients diagnosed with Crohn's disease in our center were retrospectively studied. The clinical-evolutionary characteristics of this population were compared with respect to the presence or absence of different extraintestinal manifestations.

Results: seventy-two patients (46\%) presented at least with one extraintestinal manifestation. Thirty-one percent were colitisrelated manifestations (22\% rheumatologic, 13\% muco-cutaneous, $4 \%$ ophthalmologic), $11 \%$ cholelithiasis, $8 \%$ nephrolithiasis, 3\% thromboembolic illness, and other manifestations were less frequent. Fourteen percent presented with more than one extraintestinal manifestation. Rheumatologic and muco-cutaneous manifestations were significantly more frequent in patients with disease confined to the colon. Cholelithiasis was significantly associated to those over 40 and also to males. Nephrolithiasis was also significantly associated to those over 40, and thromboembolic illness was linked to females.

Conclusions: forty-six percent of patients with Crohn's disease presented at least with one extraintestinal manifestation. Thirty-one percent presented with colitis-related manifestations, rheumatologic and muco-cutaneous manifestations being the most frequent, whereas hepatic manifestations were infrequent. Rheumatologic and muco-cutaneous manifestations were more frequent in patients with disease confined to the colon.
\end{abstract}

Key words: Crohn's disease. Extraintestinal manifestations. Prevalence.

Recibido: 28-11-05.

Aceptado: 31-01-06

Correspondencia: Alejandro Repiso Ortega. Servicio de Aparato Digestivo. Hospital Virgen de la Salud. Avda. Barber, 30. 45004 Toledo. e-mail: arepiso@sescam.jccm.es
Repiso A, Alcántara M, Muñoz-Rosas C, Rodríguez-Merlo R, Pérez-Grueso MJ, Carrobles JM, Martínez-Potenciano JL. Extraintestinal manifestations of Crohn's disease: prevalence and related factors. Rev Esp Enferm Dig 2006; 98: 510-517.

\section{INTRODUCTION}

Twenty-five to thirty-five percent of patients with inflammatory bowel disease (IBD) suffer one or more extraintestinal manifestations $(1,2)$. These manifestations are observed both in Crohn's disease and in ulcerative colitis. In some series, a greater prevalence has been described in patients with Crohn's disease (3).

Some extraintestinal manifestations, be they rheumatologic, muco-cutaneous or ophthalmologic, have been related to the colonic affectation of IBD, whereas other manifestations like nephrolithiasis and cholelithiasis have been observed with increased frequency in patients with smallbowel affectation $(4,5)$. Some of these manifestations are related to the activity of bowel disease, whereas others have an independent course (1). Nevertheless, the epidemiological, clinical and evolutionary variables that can influence the appearance and development of extraintestinal manifestations have not been clearly defined.

The aim of our study was to evaluate the prevalence of extraintestinal manifestations in patients with Crohn's disease in our healthcare area, and to assess the relationship between its presence and diverse clinical-evolutionary variables.

\section{MATERIAL AND METHODS}

We have studied, retrospectively, the extraintestinal manifestations of 157 patients diagnosed with Crohn's 
disease at "Virgen de la Salud" Hospital, Toledo, Spain, between January 1980 and December 2003. This thirdlevel hospital gives medical assistance to a population of 323,000 people. All patients fulfilled at least two Lennard-Jones criteria (6).

Extraintestinal manifestations were divided into three groups: the first group consisted of "colitis-related" manifestations including: muco-cutaneous, rheumatologic, and ophthalmologic manifestations. The second group included manifestations "related to the pathology of the small bowel", such as nephrolithiasis and cholelithiasis. The third group was composed of manifestations that could not be clearly classified under one of the other two groups, such as hepatic manifestations, amyloidosis, and thromboembolic illness.

The presence or absence of the different extraintestinal manifestations was compared to the epidemiological, clinical and evolutionary characteristics of this population. The variables included in this study were: age at diagnosis of IBD, separating the patients into two groups (those over 40 and those at 40 and under), sex, existence of a family history of IBD; a history of smoking; a history of surgery in relation to intestinal diseases, considering as such intestinal resections and/or the derivative surgeries; location of intestinal disease, which could be colonic, ileocolic or ileal; the clinical form of intestinal disease according to the Vienna classification (7), which differs from ulcero-inflammatory, obstructive and fistulizing forms; the presence of perianal disease; a history of intestinal complications, considering as such intestinal obstruction, perforation, existence of complex fistulas, and intra-abdominal abscesses; in laboratory tests, the presence of anemia at some point during follow-up, considering as such a low hemoglobin count of less than $10 \mathrm{~g} / \mathrm{dl}$ in women or less than $11 \mathrm{~g} / \mathrm{dl}$ in men; in the histological study, the presence of granulomas in endoscopic biopsies or in those in which it was present in the operative piece; and finally, the need of immunomodulator treatment at some point in the evolution, to control the symptoms of disease.

Differences were analyzed with the Chi-squared test and, when at least more than $25 \%$ of values expected were below 5, using Fisher's test. p values below 0.05 were considered statistically significant.

\section{RESULTS}

We included 157 patients in this study, all diagnosed with Crohn's disease in our health care area, with an average age of $41.15 \pm 14.5$ years, of which 89 were males and 68 females. The epidemiological, clinical and evolutionary characteristics of these patients are gathered in table I.

Seventy-two patients (46\%) presented with at least one extraintestinal manifestation. Thirty-one percent were colitis-related manifestations ( $22 \%$ rheumatologic, $13 \%$
Table I. Epidemiological, clinical and evolutionary characteristics of 157 patients with Crohn's disease

\begin{tabular}{|c|c|c|c|}
\hline & & umber of patients & Percentage (\%) \\
\hline \multicolumn{2}{|l|}{ Family history of IBD } & 20 & 13 \\
\hline \multicolumn{2}{|l|}{ History of smoking } & 103 & 65 \\
\hline \multicolumn{2}{|l|}{ History of surgery } & 43 & 27 \\
\hline \multirow[t]{3}{*}{ Location: } & lleum & 46 & 29 \\
\hline & lleum and colon & 69 & 44 \\
\hline & Colon & 42 & 27 \\
\hline \multirow[t]{3}{*}{ Clinical form: } & Ulcero-inflammatory & 92 & 59 \\
\hline & $\begin{array}{l}\text { Obstructive } \\
\text { Fistulizing }\end{array}$ & 36 & 23 \\
\hline & & 29 & 18 \\
\hline \multicolumn{4}{|l|}{ Perianal disease } \\
\hline & & 52 & 33 \\
\hline \multicolumn{4}{|c|}{ Intestinal complications } \\
\hline \multicolumn{4}{|l|}{ Anemia } \\
\hline & & 38 & 24 \\
\hline \multicolumn{4}{|l|}{ Granulomas } \\
\hline & & 39 & 25 \\
\hline \multicolumn{2}{|c|}{ Immunomodulator therapy } & 35 & 22 \\
\hline
\end{tabular}

muco-cutaneous, $4 \%$ ophthalmologic), $11 \%$ cholelithiasis, $8 \%$ nephrolithiasis, $3 \%$ thromboembolic illness, and $1 \%$ amyloidosis. Other manifestations were less frequent (Tables II and III). Fourteen percent of patients presented with more than one extraintestinal manifestation.

Colitis-related extraintestinal manifestations were significantly more frequent in patients with their disease confined to the colon $(p<0.05)$. We observed no statistically significant difference regarding its presence and females $(\mathrm{p}=0.09)$, ulcero-inflammatory clinical form $(\mathrm{p}=$ $0.12)$, anemia $(p=0.11)$, absence of intestinal complications $(\mathrm{p}=0.10)$, and presence of granulomas $(\mathrm{p}=0.15)$ (Table IV).

Of these colitis-related manifestations, rheumatologic manifestations were significantly more frequent in patients with their disease confined to the colon $(p<0.05)$, whereas mucocutaneos manifestations were observed more frequently in females $(\mathrm{p}<0.05)$ and in colonic locations $(\mathrm{p}<0.05)$. We observed no statistically significant

Table II. Extraintestinal manifestations in 157 patients with Crohn's disease

\begin{tabular}{lcc}
\hline & Number of patients & Percentage (\%) \\
\hline Extraintestinal manifestations & 72 & 46 \\
More than one extraintestinal & 22 & 14 \\
manifestation & 48 & 31 \\
Colitis-related manifestations & 35 & 22 \\
$\quad$ Rheumatologic & 20 & 13 \\
$\quad$ Mucocutaneous & 7 & 4 \\
$\quad$ Ophthalmologic & 17 & 11 \\
Cholelithiasis & 12 & 8 \\
Nephrolithiasis & 5 & 3 \\
Thromboembolic illness & 2 & 1 \\
Amyloidosis & 2 & 1 \\
Hepatic & & \\
\hline
\end{tabular}


Table III. Colitis-related extraintestinal manifestations in $\mathbf{1 5 7}$ patients with Crohn's disease

\begin{tabular}{ccc}
\hline & $\begin{array}{c}\text { Number of } \\
\text { patients }\end{array}$ & Percentage (\%) \\
\hline Rheumatologic & 17 & 11 \\
Arthralgia & 6 & 4 \\
Peripheral arthritis & 9 & 6 \\
Spondylitis/Sacroilitis & 2 & \\
Peripheral/Central arthritis & 3 & 5 \\
Aphtous stomatitis & 8 & 6 \\
Erythema nodosum & 9 & 1 \\
Pyoderma gangrenosum & 1 & 1 \\
Neutrophilic dermatitis & 2 & \\
Mucocutaneous & & 2 \\
Uveitis & 4 & 2 \\
Episcleritis & 3 & \\
\hline
\end{tabular}

Table IV. Relationship of colitis-related extraintestinal manifestations with other epidemiological, clinical and evolutionary variables

\begin{tabular}{|c|c|c|c|}
\hline & $\begin{array}{l}\text { Colitis-related } \\
\text { extraintestinal } \\
\text { manifestations }\end{array}$ & $\begin{array}{l}\text { Non colitis-related } \\
\text { extraintestinal } \\
\text { manifestations }\end{array}$ & p value \\
\hline Age $(\geq 40)$ & 25 & 54 & N.S. \\
\hline Sex: & 26 & 42 & N.S. \\
\hline Male & 22 & 67 & N.S. \\
\hline History of family IBD & 4 & 16 & N.S. \\
\hline History of smoking & 31 & 72 & N.S. \\
\hline History of surgery & 9 & 34 & N.S. \\
\hline \multirow[t]{3}{*}{ Location: } & 9 & 37 & N.S. \\
\hline & 19 & 50 & N.S \\
\hline & 20 & 22 & $p<0.05$ \\
\hline & 33 & 59 & N.S. \\
\hline $\begin{array}{r}\text { Clinical form: ulcero-inflammatory } \\
\text { Obstructive }\end{array}$ & 8 & 28 & N.S \\
\hline $\begin{array}{ll} & \text { Fistulizing }\end{array}$ & 7 & 22 & N.S \\
\hline \multirow{2}{*}{$\begin{array}{l}\text { Perianal disease } \\
\text { Intestinal complications }\end{array}$} & 18 & 34 & N.S. \\
\hline & 11 & 41 & N.S. \\
\hline Anemia & 16 & 22 & N.S. \\
\hline Granulomas & 16 & 23 & N.S \\
\hline Immunomudulators treatment & 14 & 21 & N.S. \\
\hline
\end{tabular}

N.S.: Indicates that the difference is not statistically significant.

difference between the presence of ophthalmologic manifestations and colonic affectation $(\mathrm{p}=0.38)$.

Cholelithiasis was significantly associated with age over 40 and males (Table V). Nephrolithiasis was significantly associated with age over 40 , and thromboembolic illness to females.

\section{DISCUSSION}

The results of this study show that a high percentage of patients with Crohn's disease suffer one or more extraintestinal manifestations. Forty-six percent of our patients presented at least one extraintestinal manifestation, and
Table V. Relationship of the presence of cholelithiasis with other epidemiological, clinical and evolutionary variables

\begin{tabular}{|c|c|c|c|c|}
\hline & & $\begin{array}{l}\text { Presence of } \\
\text { cholelithiasis }\end{array}$ & $\begin{array}{l}\text { Absence of } \\
\text { cholelithiasis }\end{array}$ & $p$ value \\
\hline Age $(\geq 40)$ & & 14 & 65 & $<0.05$ \\
\hline \multirow[t]{2}{*}{ Sex: } & Female & 2 & 66 & N.S. \\
\hline & Male & 15 & 74 & $<0.05$ \\
\hline Family history of IBD & & 1 & 16 & N.S. \\
\hline History of smoking & & 7 & 10 & N.S. \\
\hline History of surgery & & 8 & 35 & N.S. \\
\hline \multirow[t]{3}{*}{ Location: } & Ileum & 8 & 38 & N.S. \\
\hline & Ileum and colon & 6 & 63 & N.S. \\
\hline & Colon & 3 & 39 & N.S. \\
\hline \multicolumn{2}{|c|}{ Clinical form: ulcero-inflammatory } & 7 & 85 & N.S. \\
\hline & Obstructive & 7 & 29 & N.S. \\
\hline & Fistulizing & 3 & 26 & N.S. \\
\hline \multirow{2}{*}{\multicolumn{2}{|c|}{$\begin{array}{l}\text { Perianal disease } \\
\text { Intestinal complications }\end{array}$}} & 6 & 11 & N.S. \\
\hline & & 9 & 43 & N.S. \\
\hline \multicolumn{2}{|l|}{ Anemia } & 4 & 34 & N.S. \\
\hline \multicolumn{2}{|l|}{ Granulomas } & 3 & 36 & N.S. \\
\hline \multicolumn{2}{|c|}{ Immunomodulator therapy } & 5 & 30 & N.S. \\
\hline
\end{tabular}

N.S.: Indicates that the difference is not statistically significant.

$14 \%$ more than one. The variability in frequency of extraintestinal manifestations described in the different series justifies itself largely by the definition used in every case. On occasion they have been considered as alterations in systems other than the digestive tract and much more frequently in patients with IBD, criteria that we use in our patients, whereas in other series only conditions autoimmune in nature and associated with intestinal disease were included (8). Secondly, the prevalence of extraintestinal manifestations will have a direct influence on the intensity of our search for them, since many of them can present with few symptoms or even a sub-clinical evolution $(9,10)$. Finally, in this type of study, the frequency of these manifestations increases with follow-up, therefore its frequency will be greater in prospective series (11) versus descriptive, transverse studies like our own.

We observed colitis-related extraintestinal manifestations in $31 \%$ of our patients, with rheumatologic and mucocutaneous manifestations being most frequent. When we compared our results with other series, which describe rheumatologic manifestations in $22-33 \%$ of patients with $\operatorname{IBD}(4,5,12,13)$ we observed that the proportion is equal to our own. Likewise, we observed a frequency of mucocutaneous and ophthalmologic manifestations similar to those described in the principal series. Nevertheless, other authors (14) have described a $40 \%$ proportion of cutaneous manifestations -much greater than our own, probably on having included, among these, perianal disease.

In our series, as in those described by other authors $(4,5)$, colitis-related extraintestinal manifestations were more frequent in colonic location of Crohn's disease. This phenomenon probably has its explanation in the loss of 
the function of the intestine as a barrier, which occurs in inflammatory intestinal conditions and, in consequence, allows the flow of certain substances into systemic circulation -mainly bacterial and food components at, predominantly, the colonic level, which would manage to reach the systemic circulation and activate the immune system, thus unleashing extraintestinal manifestations (15). In our patients we observed a greater frequency of colitis-related extraintestinal manifestations in the female sex, which did not reach statistical significance. This predominance in women, as seen in many other autoimmune conditions, may only be in relation to certain hormonal influences in the immune system.

As for small bowel-related manifestations, we observed that cholelithiasis was more frequent in males. The explanation might be related to a greater numbers of males with ileal affectation in our series, and -as mentioned before $(16,17)$ - ileal affectation would alter the "pool" of bile acids and then allow the formation of bile stones.

We observed a greater frequency of nephrolithiasis in patients over 40 at the time of diagnosis of intestinal disease, which precisely represents the age group between 30 to 50, in which a greater frequency has been described regarding nephrolithiasis (18).

Thromboembolic illness was associated with age over 40 and females, probably due to the coexistence in this patient subgroup of hormonal factors and trombophilic factors that are characteristic of IBD, including thrombocytosis and an increase in some coagulation factors and platelet aggregation (19).

We observed a low prevalence of hepatic extraintestinal manifestations in our patients that did not exceed $1 \%$, whereas in some series more than $15 \%$ of patients (with IBD) are reported to have altered hepatic tests (20). Nevertheless, great numbers of these are related to alterations in liver biochemistry from nutritional disorders, inflammatory chronic conditions, parenteral nutrition, and pharmacological toxicity. We included as liver-related extraintestinal manifestations only those of autoimmune origin, including pericholangitis, sclerosing cholangitis, and autoimmune hepatitis, which justifies this low percentage.

In conclusion, $46 \%$ of patients with Crohn's disease presented with at least one extraintestinal manifestation, and thirty-one percent were colitis-related manifestations. Rheumatologic and mucocutaneous manifestations were most frequent, whereas hepatic manifestations were infrequent. Colitis-related manifestations were more frequent in the colonic location.

\section{REFERENCES}

1. Su CG, Judge TA, Lichtenstein GR. Extraintestinal manifestations of inflammatory bowel disease. Gastroenterol Clin N Am 2002; 31: 307-27.

2. Lakatos L, Pandur T, David G, Balogh Z, Kuronya P, Tollas A, et al. Association of extraintestinal manifestations of inflammatory bowel disease in a province of western Hungary with disease phenotype: results of a 25-year follow-up study. World J Gastroenterol 2003; 9: 2300-7.

3. Veloso FT, Carvacho J, Magro F. Immune-related systemic manifestations of inflammatory bowel disease. A prospective study of 792 patients. J Clin Gastroenterol 1996; 23: 29-34.

4. Greenstein AJ, Janowitz HD, Sachar DB. The extra-intestinal complications of Crohn's disease and ulcerative colitis: Study of 700 patients. Medicine 1976; 55: 401-12.

5. Abreu L, Abascal J, Barrios C, Escartín P, Garrido J, Moscardó J, et al. Manifestaciones extraintestinales de la enfermedad de Crohn. Estudio de 110 casos. Gastroenterol Hepatol 1981; 4: 165-70.

6. Lennard-Jones JE. Classification of inflammatory bowel disease. Scand J Gastroenterol 1989; 170 (Supl.): 2-6.

7. De Gasche C, Scholmerich J, Brynskov J, D'Haens G, Hanauer SB, Irvine EJ, et al. A simple classification of Crohn's disease: report of the Working Party for the world Congresses of Gastroenterology, Viena, 1998. Inflam Bowel Dis 2000; 6: 8-15.

8. Bernstein CN, Blanchard JF, Rawsthorne P, Yu N. The prevalence of extraintestinal diseases in inflammatory bowel disease: a population-based study. Am J Gastroenterol 2001; 96: 1116-22.

9. Verbraak FD, Schreinemachers MC, Tiller A, Van Deventer SJ, De Smet MD. Prevalence of subclinical anterior uveitis in adult patients with inflammatory bowel disease. Br J Ophthalmol 2001; 85: 219-21.

10. Queiro R, Máiz O, Intxausti J, de Dios JR, Belzunegui J, González $\mathrm{C}$, et al. Subclinical sacroiliitis in inflammatory bowel disease: a clinical and follow-up study. Clin Rheumatol 2000; 19: 445-9.

11. Mendoza JL, Lana R, Taxonera C, Alba C, Izquierdo S, Díaz-Rubio M. Manifestaciones extraintestinales en la enfermedad inflamatoria intestinal: diferencias entre la enfermedad de Crohn y la colitis ulcerosa. Med Clin 2005; 125: 297-300.

12. Rankin GB, Watts D, Melnyk CS, Kelley ML. National cooperative Crohn's disease study: extraintestinal manifestations and perianal complications. Gastroenterology 1979; 77: 914-20.

13. Crespo-Urigüen C, Pérez-Lozana JR, Pérez-Suárez A, Miyar-González A. Manifestaciones extraintestinales de la enfermedad de Crohn: nuestra experiencia. Rev Esp Enferm Dig 1991; 80: 169-72.

14. McCallum DI, Kinmont PC. Dermatologic manifestations of Crohn,s disease. Brit J Dermatol 1968; 80: 1-4.

15. Levine JB, Lukawski-Trubish D. Extraintestinal considerations in IBD. Gastroenterol Clin North Am 1995; 24: 633-46.

16. Lapidus A, Bangstad M, Astrom M, Muhrbeck O. The prevalence of gallstone disease in a defined cohort of patients with Crohn's disease. Am J Gastroenterol 1999; 94: 1261-6.

17. Lorusso D, Leo S, Mossa A, Guerra V. Cholelithiasis in inflammatory bowel disease. Case-control study. Dis Colon Rectum 1990; 33: 791-6.

18. Leiva O, Diaz R. Litiasis urinaria. En: Levia O, Diaz R, editores. Urología. Madrid: Luzán 5 S.A. de ediciones; 1995. p. 261-92.

19. Papa A, Danese S, Grillo A, Gasbarrini G, Gasbarrini A. Review article: inherited thrombophilia in inflammatory bowel disase. Am J Gastroenterol 2003; 98: 1247-51.

20. Balan V, Larusso NF. Hepatobiliary disease in inflammatory bowel disease. Gastroenterol Clin North Am 1995; 24: 647-69. 